\title{
Tactile Behaviour of Greek Preschool Teachers
}

\section{Panagiotis J. Stamatis, Anastasios Th. Kontakos}

Department of Sciences of Preschool Education and Educational Design (TEPAES), University of the Aegean, Rhodes

\section{Greece}

stamatis@rhodes.aegean.gr

Dr. Panagiotis J. Stamatis. University of the Aegean, GR-851 01 DAMATRIA, RHODES, Greece. E-mail: stamatis@rhodes.aegean.gr

(C) Education \& Psychology $\mathrm{I}+\mathrm{D}+\mathrm{i}$ and Editorial EOS (Spain) 


\begin{abstract}
Introduction. The sense of touching is positively related to a number of environmental stimuli and forms an effective way of non verbal communication. More specifically, it can produce and transmit various personal experiences in the context of what we call 'beneficial touching behaviours', which characterise the ongoing pedagogical process. The investigation of touching behaviour of preschool teachers, namely of their perceptions and their practical applications in the context of preschool classrooms, can generate numerous and pedagogically useful conclusions which elicit the main aspects between perceptions and proceedings as well as the constructive contribution of touching behaviour in the child's developmental communication process.
\end{abstract}

Method. Gathering data by a questionnaire which focused on preschool teacher's perceptions about pedagogical dimensions of touch is the main technique of the present research in parallel with classroom observation and video-analysis.

Results. The descriptive statistics provide interesting elements in a quantitative level previously about the characteristics of children and preschool teacher's touching behavior and secondly about the reasons of between them interactions.

Conclusión. In spite of preschool teacher's strong beliefs that touch improves interpersonal communication skills and contributes to creation of a strong relationship between children and teachers, they unconsciously seem to avoid touch or to be touched by children.

Keywords: tactile behaviour, touch, classroom interaction, tactile communication, communication in education

Received: 02/08/08 Initial Acceptance: 02/19/08 Final Acceptance: 03/31/08 


\section{Resumen}

Introducción. El sentido del tacto se relaciona positivamente con numerosos estímulos y formas del entorno dando lugar a una forma efectiva de comunicación no verbal. Más específicamente, puede producir y transmitir experiencias personales dentro de lo que denominamos “comportamientos táctiles beneficiosos" que caracterízan el proceso pedagógico presentado. La investigación sobre comportamientos táctiles de profesorado de Educación Infantil, y sus aplicaciones prácticas en las aulas, puede generar numerosas conclusiones pedagógicamente útiles dado que explicita las relaciones entre percepciones y procedimientos, así como la contribución del sentido del tacto en el desarrollo del proceso de comunicación de los niños.

Metodo. Los datos se obtienen a través de un cuestionario centrado en las percecpciones del profesorado de preescolar sobre las dimensiones pedagógicas del tacto. Además se utiliza la observación y el análisis de vídeos.

Resultados. Los estadísticos descriptivos proporcionan, en primer lugar, elementos cuantitativos interesantes sobre las características de los niños y del profesorado en relación con los comportamientos táctiles, y en segundo lugar, las razones de las interacciones entre ellos.

Conclusión. A pesar de la fuerte creencia del profesorado sobre la importancia del tacto para el desarrollo de la comunicación interpersonal y para la creación de relaciones profesor/alumno positivas son muchos, los que inconscientemente, parecen evitar tocar o ser tocados por los niños.

Palabras Clave: comportamiento táctil, tacto, interacción en el aula, comunicación táctil, comunicación en educación.

Recibido: 08/02/08 Aceptación Inicial: 19/02/08 Aceptación Definitiva: 31/03/08 


\section{Introduction}

The sense of bodily touch has been characterized as the 'mother of all senses' and the skin, the 'sensory body' with which it becomes perceptible, as the "exterior brain of" human beings and animals (Montagu, 1986). It has been acknowledged that the importance of touch and more specifically the touching behaviour is exceptionally important for humans, especially as the foetus develops, since it is related to numerous beneficial factors. For example, we could mention biological, psycho-affective and intellectual factors (Bushnell \& Boudreau, 1993; Field, 2001; Hatfield, 1994; Papadaki-Michaelidi, 2002). More specifically, the experience of the feeling of touch contributes to the proper function of all the vital systems of our body, the growth of our bones, the strengthening of our feelings, such as safety, selfconfidence and recognition, the reduction of stress levels and the normal development and proper function of our cerebral hemispheres in our brain. The beneficial effects of touching behaviour are not only limited to the early years of our existence but are also reported throughout our life. Research findings indicate that we can anticipate a normal social behaviour in adults who were subjected to a number of positive touching experiences, mainly at the preschool and primary school's age, contrary to individuals that did not experience or were not subjected to comparable experiences (Prescott, 1990).

The act of touching constitutes, at the same time, part of a wider, non verbal, communication of a person that, as a vital habit, depends on various factors, such as sex, age, the socio-economic, education level and cultural context (Kodakos \& Polemikos, 2000). It can also affect the configuration of "touching communication", the tactile communication (Stevenson \& Poole, 1976) which also leads to a wider, non verbal, communicational spectrum that involve mainly the facial communication, the characteristics and the postures of the body and also gestures, movements of the head, and expressions of the individual (Kotzman, 1989; Miller, 2000).

Touching behaviour is perceived as a means of communication that comprises the contact and touching experiences it creates. These experiences compose various non verbal messages that function as a base for the creation of a particular communication frame, the "touching" frame. The communication of touching can be susceptible to various interpretations and involves different meanings and contents when perceived in different communication environments where a range of formative elements exist, such as cultural, racial, social, eco- 
nomic, personal, and religious ones. We could also identify other kinds of touches, such as the professional touch of a doctor during surgery or the patting and stroking at the hairdresser's. Handshakes and other 'rubs' between two adults of the opposite or same sex or even a hug from a stranger are distinctively different to the warm hug of a parent (Stamatis, 2005).

According to our bibliographic sources, the role of contact in the bodily growth and in the behavioural development was initially investigated by Hammet in 1922 in his experiments with rats. His research revealed that when rats had got touching experiences (experimental team) and had the thyroid gland removed, demonstrated much bigger rates of viability than those rats that were also operated but not exposed to touching experiences (control team). The fact that the control team was kept in a clean cage and enjoyed good food appeared to have a positive influence on their viability. In the experimental team only $13 \%$ of the rats died against $76 \%$ from the control team. Hammet concluded that the variable which decisively influenced rats vitality was the positive effect of touching, which is widely acknowledged as the vital cause of life (Kay, 1998).

The fundamental importance of touching was pointed out by Spitz, who investigated the sudden and unprovoked biologically deaths of children in orphanages in Romania during 1947. Spitz observed initially those children who were not touched or subjected to any kind of affection. They displayed retardation upon bodily and intellectual growth as well as behavioural problems during their socialisation process. This phenomenon was named 'hospitalism' and its negative consequences unfortunately contributed to the death of those children. The outcomes of his research were also confirmed by Harlow in 1958 and 1962 (Hatfield, 1994) who provided evidence for lack of the "tender bodily contact" (contact comfort). Harlow is considered the father of scientific research on the subject of the bodily contact. He also conducted experiments with young apes. While observing their behaviour under the presence of two scarecrows, the first one was fed from a wire that offered food and the second dressed with soft buckram that it did not offer food; the young apes preferred the second one. This result was attributed to the heat that emerged from the contact with the buckram. The scientific interest in bodily contact and its consequences began substantially to arise during the 1950's when Montagu wrote his first article about the importance of skin as a supreme sensory organ. This article constituted the inspiration for him to write an important book later entitled 'The human significance of the skin', which is considered essential for the study of touch. 
At the same time with Harlow, Bowlby and his associate Ainsworth dealt with the relations that are developed between nurslings and their parents and mainly how these develop or fail in the contracting of beams. Their longitudinal researches mainly in primitive societies existed constantly with the work of Lorenz in 1952. The inquiring conclusions about the importance of touching behaviour and particularly the research of Harlow led to the formulation of the "Theory of Contracting of Relations" (Attachment Theory), which focuses on the interpretation of the innate possibility of growth of interpersonal beams with emphasis on the interaction between mothers and their infants (Hatfield, 1994). His research focused for decades on this subject offering useful conclusions in the field of evolutionary psychology. Schneider (1996) claims that Rice in 1976 proved that infants that were given massages acquired weight faster and their neurological growth became bigger. She also claims that Hansen and Ulrey in 1980 observed infants with kinetic problems and found that through contact infants presented better results. In 1996, Field, Grizzle, Scafidi, Abrams \& Richardson, experimented studying the bodily growth of children that were given massage three times a day from fifteen minutes each time related to others who did not enjoy the same care. The results showed that the former presented $47 \%$ more growth of weight, good disposal and health than the latter. According to Schneider (1996) study was repeated one year later by White-Trout who confirmed the same results of the research carried out previously by Field. The same results are also found in the work of Scafidi, Field, Schanberg \& Bauer, 1990. A proportional research of Unvas-Mosberg in 1989 according to Schneider (1996) proved that the contact of infants' body on the breast, when breast feeding, contributes to the excretion of two hormones, gastrin and insulin, that are necessary for the nutritious operation of an organism.

We need to emphasise that researchers who examined the bodily contact from the viewpoint of non verbal communication deserve credit in our concise historical retrospection. Hall (1959) studied the behaviour of persons regarding interpersonal distances (proximity). Jourard (1966) studied and recorded the points of contact between same and different sex's interpersonal interactions. Morris (1971) observed regularly the human touching behaviour. Henley (1977) initially conducted individual research and then with her associate LaFrance (1984) they studied the inter-sex non verbal behaviour where the touching factor was incorporated. Burgoon (1992) dealt mainly with the types of handshake and the social importance of each one. Ritchmont and his collaborator McCroskey (2000) studied non verbal behaviour in the cross-cultural and international relations (Stamatis, 2005). Research on the beneficial attributes of non verbal or touching behaviour is generally continued today with particular 
interest in specialised academic centres and research institutes (Phan, 2006; Rivas-Martinez, 2007; Was, 2006). In the field of education, the pedagogical importance of contact, which is in close, positive relation to the term "pedagogic touching", was investigated revealing interesting conclusions for the importance of touching in the bodily, mental and intellectual growth of a person and especially during the first years of his/her life, mainly in the I.P.A., by Field (2001), which have published her conclusions in her book titled "Touch". Analogous researches that consider the contact in the field of education as a fundamental strategy for improving the non verbal communication difficulties of children are carried out in Greece by Kodakos and Polemikos (2000) and Vrettos (2003). Papadaki-Michaelidi (2002) also deals with the beneficial consequences of touching.

\section{Rationale and hypotheses}

In this research our interest focuses on the period where communication of preschoolers is related to the growth of positive touching behaviours, which are parallel with other ones, as part of a wider pedagogical strategy that aims, due to the beneficial effects of contact, to the most effective education of infants. Infants are sensitive recipients of non verbal messages that, however often, can be misinterpreted, with unanticipated bioemotional and pedagogical consequences, because weakness of complete analysis and interpretation (Wellman, Phillips \& Rodríguez, 2000). Touching and more generally contact that encourages touching behaviour between preschool teachers and infants include opportunities of non verbal messages that depend on the wider communication frame of the moment (Harris, Petersen, \& Diamont, 1999). Touching plays a particularly important role in the configuration of interpersonal relations among infants (Carlson, 2002; Cigales et al., 1996) and between infants and preschool teachers (Frymier \& Mongeau, 1997). This role involves a lot of other "socio political" results, becomes long-lasting comprehensible (Field, 1999). The above ascertainment constitutes the stimulus to investigate touching that is developed in the kindergarten during the daily participation in activities within the framework of "touching dimension" of pedagogical communication, which we consider as an appreciable parameter for the growth of pedagogical strategies and educational planning. More concretely, our reflection focuses, on one hand, on the study of perceptions of preschool teachers regarding the touching behaviour between them and the infants and, on the other hand, on the confirmation of these degrees of transubstantiation or perceptions in the daily early childhood practice. In other words, the aim of our empirical research was the confirmation, at a descriptive level, of the perceptions of preschool teachers on one side and the observation of their touching behaviours on the other 
side, so that the affinity between perceptions and touching has practical and communication expediency.

According to the previous researches and the theories on touching behaviour and the multiple beneficial importance of contact was developed by the present research so that the following hypotheses were investigated:

H1. Greek early childhood teachers express frequent touching behaviour (bodily contacts and pedagogical touching) with the preschool children.

H2. The touching behaviour that is expressed between Greek preschool teachers and preschool children has mainly communication expediency.

H3. the event of contact constitutes positive motive of communication in the early childhood period.

\section{Method}

\section{Participants}

Permanent preschool teachers working in the area of Aegean (Lemnos, Lesvos, Chios, Samos, Cyclades and the Dodecanese islands) were called to fill in the questionnaire that was handed out on the first exploratory level. A hundred one preschool teachers (101) responded to the invitation (they constitute $15 \%$ of the total population permanently placed and aged between 35 and 45 years) who attended the Program of Academic In-service for a two-year professional development at the Centre "Konstantinos Karatheodoris" of the Department of Sciences of Preschool Education and Educational Design of the University of the Aegean (T.E.P.A.E.S.). The observation that took place at the second exploratory phase included ten half-hour activities at kindergarten centres in Rhodes that were randomly selected by the method of accidental sampling. Ten preschool teachers and one hundred and thirty four preschool children were observed in their communication interactions during the concretisation activities for aesthetic education in the early childhood years.

\section{Instrument}

For the observation of touching behaviours in connection with their communication and pedagogical dimensions the S.A.T.B. was specifically designed to constitute four categories of observation. Each one has the possibility of recording precisely the points of contact on the body and the two dependent variables, the duration of each contact, the aim of each contact and the communication results of each contact. The variables of the research were 
later codified after they had been described in detail in a special 'code book' that presented analytically the characteristics of all variables of S.A.T.B. Consequently, the 'code book' presents three fields of observation and investigation. The first one includes all the related elements for the form and the type of contact, the bodily point of contact and the duration of touching, which was then examined in ten sub classes. The second field presents elements for the comprehension of contact, the main aim of event and the form of interaction that continued. Finally, the third field presents five subclasses in the description of the communication frame as the atmosphere of period, the interpersonal distance etc, according to the non verbal factors, which affect interpersonal communication and interaction during this particular period (proxemics, environmental conditions, etc). During the course of the investigation, relations on the research were placed on the following criteria based on which the answers could be also measured consequently are appreciated by their degree of importance (a) as 'frequent touching behaviour' is comprehended the deliberate growth of contacts which lasts at least 5$8 \mathrm{sec}$ and is repeatedly practised in each child per regular time intervals (b) as 'communication' is comprehended the fact that the preschool teachers participating in the communication process aim to the transmission as well as to the comprehension of homiletics of action with explicit intention and explicit result that is absolutely harmonised with the intention (c) the event of contact is considered to contribute constructively in the materialisation of communication in the early childhood period when such situations are observed as the growth and continuation of dialogue between preschool teachers and infants or among infants alone.

\section{Procedures}

Method procedures research was structured according to the plan of conduct in the two exploratory levels, which are described below, and was completed in the year 2003. The first exploratory level included the completion of a questionnaire with the perceptions of preschool teachers in regard to the touching behaviour between them and the preschool children in the context of their daily educational action. Also, it included the perceptions preschool teachers have for the pedagogic usefulness of growth of touching behaviours with the infants. The questionnaire included ten closed type questions which aimed on one hand to detect touching habits of preschool teachers and preschool children and on the other hand to detect perceptions of preschool teachers for the expediency, the communication and the pedagogical importance of touching during their daily interaction in the early childhood period. The second exploratory level initially included the video recording and then the observation with the 
technique of a video analysis of touching behaviours expressed in the early childhood period during the concretisation of activities related to aesthetic education.

The observation and the recording of touching behaviour were validated by three independent observers who recorded the empirical data in a special piece of work entitled "Systemic Analysis of Touching Behaviours" (S.A.T.B.). After the empirical data were crossed, they were imported for statistical analysis. The statistical software which was used was StatView II (Mac).

\section{Results}

As they were observed minimum contacts were marked -and in particular most of them accidental- despite the growth of intense approximate behaviour between preschool teachers and infants. This fact does not verify the first relation of research opinion which is also strengthened by the small time of duration touching. In regard to the duration touching it was so much realised by the questionnaires and by the video analysis that $79 \%$ of them did not exceed 1-3 sec. It is, that is to say, substantially slightly touching mainly in the head, in the back-shoulder and in the hands of preschool children, that is to say on the socially acceptable areas. The fact that in the perceptions preschool teachers, as they are recorded in the questionnaire, presented difficulty in the determination of time duration touching in their references, also, in the existence of ambiguity for their particular behaviour, that is to say, lack of conscience that it implies to some degree the degrading of the subject. Each cognisant of touching behaviour is related to concrete expediency, which contributes to the configuration of proportional pedagogical relation. This expediency is, at a declining line, sentimental (42\%), which aims at the transmission of sentiments, communication (35\%), which aims at the beginning and materialisation of communication process, the leading (17\%), which seeks the control of behaviour of infants and nursing $(6 \%)$, which aims at the care of infants. Also, the expediency of touching, while it is considered as pedagogically useful strategy, was found at the same time "to exude sentimental distance" as the touching is usually used for the attracting of attention, the formal transmission of sentiments and the functionalism (negligence or control of behaviour of infants and adults). Related to the above findings is the purposefulness of touching which, however primarily considered for the intensification of pedagogically interrelated relationships, was found from the first exploratory level that partially confirms this perception of preschool teachers. Additionally, on the second exploratory level, it was observed 
that the touching "exuded sentimental distance" was often apparent for reasons of discipline in classroom. Consequently, the second hypothesis of our research which is partially verified as the communication expediency, even if it is recorded in the findings of our research, represents the secondary level of the expediency of contacts (35\%) of preschool teachers.

As it was observed, the event of contact contributed constructively to the materialisation of communication in the early childhood period, because conditions were observed as the growth and the continuation of the dialogue between preschool teachers and preschool children and among preschool children. The touching stimulus was found to constitute a powerful motive of communication ( $83 \%)$, as part of the communication interactions that were reported. Following the touching, dialogues mark the constant exchange of verbal and non verbal messages. The degree of correlation between touching behaviour and improvement of communication process was found exceptionally high $(\mathrm{p}=.0001)$ and hence it is confirmed that the third hypothesis of our research is verified.

\section{Discussion and conclusions}

The touching, even if it constitutes in Greece a form of expressing love and consequently permissible, represents a social behaviour with multiple biophysical effects (Stamatis, 2005). While it is considered as structural element of pedagogical interaction-communication by early childhood teachers, and generally conceived as pedagogically useful, it is usually avoided in the daily early childhood practice, as it was recorded in our research. Based on the analysis and interpretation of our statistical results and in regard to the previous researches, the theory for the beneficial repercussions of contact on young children has mainly observed that in general touching behaviour between preschool teachers and preschool children is not expressed spontaneously. At the same time, even if it represents the impersonal, public, social admissions, it is incriminated, subconsciously, and affects its pedagogical value as disregards the structural elements of growth and familiarity. We need to underline, based on our findings, that early childhood teachers almost always touch preschool children's hands, their head (hair) and their back or their shoulders while the infants touch their teachers in their hands. Thus, the event of touching behaviour constitutes a strictly controlled pedagogical formal we would say- behaviour that usually complies with familiarity, interpersonal, spontaneous behaviour. This detachment from its main pedagogical role is crucial and does not constitute a 'pedagogical touch'. The touching behaviour comprises a conjunctive 'ring' bet- 
ween communication intentions and communication results and contributes to the configuration of a positive pedagogical climate. This conclusion results from responses of preschool teachers who believe that reciprocal touching behaviour contributes to the intensification of pedagogical relation affecting bio-emotional and interpersonal relations. It was also confirmed by the two exploratory levels that most touching of infants, provided that it was not recorded as accidental, aimed to attract the attention of early childhood teachers. At the same time early childhood teachers also contributed to the cultivation of positive sentiments targeting the removal of sentimental insecurity of infants, their encouragement and the maintenance of a positive pedagogical climate. In this case, the ethical dimension of touching is presented as constituting the culmination of pedagogical, non verbal communication-interactive strategy, provided that sentiments and information are not verbally transmitted, as it is pointed out in the bibliography (Argyle, 1988; Burgoon \& Guerrero, 1994).

The development of touching behaviours was found both under qualitative and quantitative analysis limited. Thus it can be inferred that it is pedagogically disproportionate. Teachers' actions described as deliberate touching reached hardly the $1 / 8$ or the $12.5 \%$ of the total instructive time during our exploratory observation. Same results were reported in research that was carried out in U.S.A. (Field, 2001). We believe that these findings are not consistent with the Greek customs associated to touching behaviour, so further investigation of the subject would have been very useful and more revealing. It has been already noted that researches that focus on the dependent variables of our research are minimal. Most of them mainly focus their interest on the observation of the forms of pedagogical interactions. Our research substantially inaugurates a modern field of investigation based on the Greek educational reality of infantile age. What is particularly impressive is the inconsistency between perceptions and actions that early childhood teachers adopt. This result is something that needs further investigation. Consequently, our findings related to teachers' attitudes do not agree with findings from other research related to benefits of 'pedagogical touching'. This can be explained by the fact that their limited professional development training and expertise associated to this subject considerably affects the ongoing communication process in the early childhood period.

The fact is that early childhood teachers present a vague opinion of touching behaviour, possibly related to socially acceptable behaviour as emanates from the Greek traditions. We also suggest that in order to make appropriate interventions, the way of life of mo- 
dern Greeks needs to be investigated. We also agree that touching constitutes not only a 'source of life' but also a dynamic factor for the establishment of a healthy non verbal communication and pedagogical relationship (Knapp \& Hall, 2002; Richmont \& McCroskey, 2000). Nevertheless, the role of pedagogical touching does not appear to become acceptable at practical level and appears to be further downgraded in a distrustful and reserved society. The lack of related knowledge can lead to the misjudgement and incrimination of the pedagogical outcomes of touching even in the context of a kindergarten. This situation leads to further formality of interpersonal relations and consequently to the alienation of preschool teachers towards their infants as they damage, often irreparably and groundlessly, the pedagogical relation, which needs permanent and continuous contribution so that it can produce better pedagogical results.

In conclusion, it is pointed out that according to our results, early childhood teachers conceive the beneficial effects and in particular the pedagogical importance of contact. Nevertheless they tend to consciously limit their touching behaviour only in impersonal, informal touching behaviours. However, it needs to be clearly emphasised that these do not constitute 'pedagogical touching'. This substantially impedes the beneficial pedagogical role of touching as implemented at the kindergarten environment. Touching then only aims to the transmission of affectionate sentiments and circumstantially to the materialisation and improvement of the communication process. This goes against the increasing understanding that touching behaviour constitutes a strategy of improvement in pedagogical communication in the context of kindergarten. Coping with this negative phenomenon by means of the reestablishment of touching behaviour within the pedagogical and communication dimension needs to be prioritised. It can be achieved by a suitable education of preschool teachers, at a level of micro teaching, aiming to the successful exchange of roles. Methods for pedagogical and suitable touching behaviours that need further investigation. We also need to acknowledge all the difficulties that emerged during our research mainly associated to the complexity and volatility of human behaviour and the particularity in the early childhood teacher's context.

Furthermore, the need for conducting further research is recognised but in a way that it will contribute positively to the amelioration of pedagogical non verbal communication. This often constitutes the most decisive factors of configuration for successful interpersonal relations, specifically in the context of preschool and elementary education. Finally, we should 
not forget that the success of the communication process ensures the foundation, structure and the aim of each educational effort that places personal teaching efficacy in the epicentre of this challenge.

\section{References}

Argyle, M. (1988). Bodily communication. New York: Metheum \& Co.

Burgoon, J.K. (1992). Interpretations, Evaluations, and Consequences of Interpersonal Touch. Human Communication Research, vol. 19, pp: 237-263.

Burgoon, J.K. \& Guerrero, L.K. (1994). Nonverbal Communication. In M. Burgoon, F.G. Hunsaker \& E.J. Dawson (Eds.), Human Communication (3d ed., pp:193-215). USA: SAGE Publication Inc.

Bushnell, E.W. \& Boudreau, J.P. (1993). Motor Development and the Mind: the potential role of motor abilities as a determinant of aspects of perceptual development. Child Development, 64, 66-82.

Carlson, F.M. (2002). Incorporating Touch in Early Childhood Settings. (Available from http://www.carlsoncastone.pdf). 5-12-2007

Cigales, M., Field, T., Hossain, Z., Pelaez-Nogueras, M. \& Gewirtz, J. (1996). Touch among Children at Nursery School. Early Childhood Development and Care, 126, 134-147.

Field, T., Grizzle, N., Scafidi, F., Abrams, S. \& Richardson, S. (1996). Massage therapy for infants of depressed mothers. Infant Behavior and Development, 19,109-114.

Field, T. (1999). Preschoolers in America are touched less and are more aggressive than preschoolers in France. Early Child Development and Care, 151, 89-97.

Field, T. (2001). Touch. The MIT Press.

Frymier, A.B. \& Mongeau, P.A. (1997). Communicating with touch in the Teacher / Student Relationship. U.S. Baltimore: Annual Meeting of the Eastern Communication Association. (Available from ERIC Database, ED 427378). 6-7-2005

Hall, E.T. (1959). The Silent Language. New York:Doubleday.

Harris, J.A., Petersen, R.S. \& Diamont, M.E. (1999). Distribution of tactile learning and its neural basis. Psychology, 96, 318-329.

Hatfield, R.W. (1994). Touch and human sexuality. In V. Bullough, B. Bullough \& A. Stein, (Eds.), Human Sexuality: An Encyclopedia, (2 ${ }^{\text {nd }}$ ed., pp:178-192). N.Y.: Garland Publishing.

Henley, N. (1977). Body Politics. London: Compendium Bookshop 
Henley, N. \& LaFrance, M (1984). Gender as a culture. Difference and no mince in non verbal behavior. In A. Wolfgang (Ed.) Non Verbal Behavior (pp:351-371). New York:Lewinston.

Jourard, S. (1966). An Exploratory Case of Body - Accesibility. British Journal of Social and Clinical Psychology, 8, 222-231.

Kay, K.M. (1998). Infant Massage- "Loving Touch”. Paper in Annual Educational Conference of International Association of Infant Massage. USA.

Knapp, M.L. \& Hall, J.A. (2002). Nonverbal Communication in Human Interaction. Wadsworth: Thomson Learning.

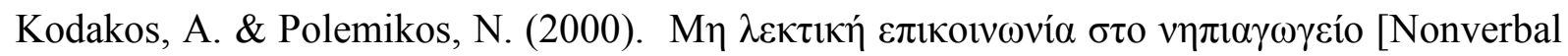
communication in kindergarten]. Athens, GR: Ellinika Grammata.

Kotzman, A., (1989). Listen to me, listen to you. A practical guide to improving self-esteem, listening skills and assertiveness. Australia: Penguin Books Ltd.

Miller, P.W. (2000). Nonverbal Communication in the Classroom. USA: P.W. Miller \& Ass. Montagu, A. (1986). Touching: The Human Significance of the Skin. New York: Harper \& Row.

Morris, D. (1971). Intimate Behavior. Jonathan Cape Ltd.

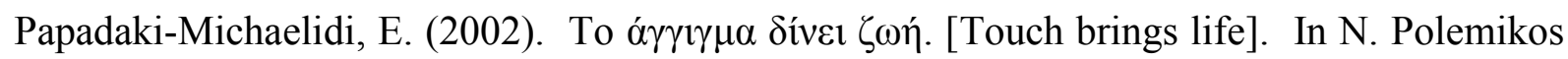

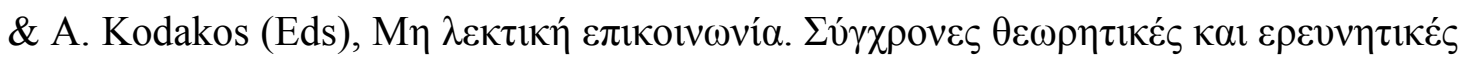

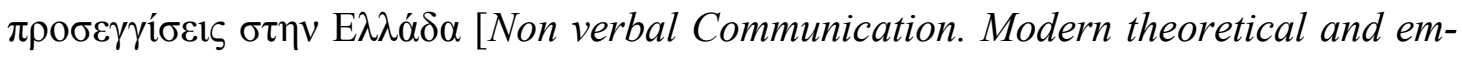
pirical approaches in Greece] ( $1^{\text {st }}$ ed., pp:71-85). Athens, GR: Ellinika Grammata.

Phan, H. P. (2006). Examination of student learning approaches, reflective thinking, and epistemological beliefs: A latent variables approach. Electronic Journal of Research in Educational Psychology, 4(3), 577-610 (www.investigacionpsicopedagogica.org/revista/new/english). 16-2-2008

Prescott, J.W. (1990). Affectional bonding for the prevention of violent behaviors: neurobiological, psychological and religious / spiritual determinants. Violent Behavior. Great Neck, NY: PMA Publishing.

Richmont, V.P. \& McCroskey, J.C. (2000). Nonverbal Behavior in Interpersonal Relations. USA: Allyn \& Bacon.

Rivas-Martinez, F. (2007). Vocational hehavior and counseling in today's world. Electronic Journal of Research in Educational Psychology, 5(1), 5-17 (www.investigacionpsicopedagogica.org/revista/new/english). 16-2-2008 
Scafidi, F.A., Field, T.M, Schanberg, S.M. \& Bauer, C.R. (1990). Massage stimulates growth in preterm infants: A replication. Infant Bahavior \& Development, Vol. 13(2), pp:167188.

Schneider, E.F. (1996). The power of touch: massage for infants. Infants \& Young Children, vol. 8 (3), pp: 40-55.

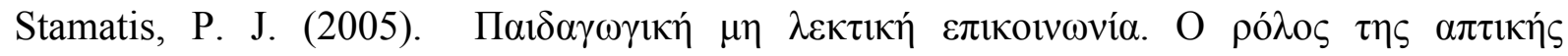

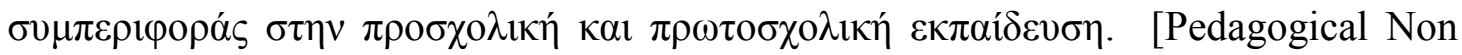
Verbal Communication. The role of tactile behavior in pre-school and first-school education]. Athens, GR: Atrapos.

Stevenson, M.F. \& Poole, T.B. (1976). An Ethogram of the Common Marmoset (Calithrix Jaccus Jaccus): General Behavior Repertoire. Animal Behavior, vol. 24, pp. 428-451.

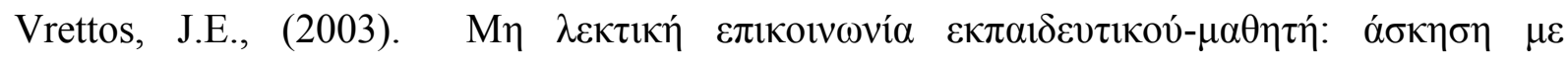
$\mu 1 \kappa \rho \circ \delta 1 \delta \alpha \sigma \kappa \alpha \lambda i \alpha^{\alpha}$ [Non verbal behavior between teacher and student: practice with microteaching]. Athens, GR: Atrapos.

Was, C. (2006). Academic Achievement Goal Orientation: Taking Another Look. Electronic Journal of Research in Educational Psychology, vol. 4(3), pp:529-550. (www.investigacion-psicopedagogica.org/revista/new/english). 16-2-2008

Wellman, H.M., Phillips, A.T. \& Rodriguez, T. (2000). Young children understanding of perception, desire and emotion. Child Development, vol. 71(4), pp:153-168. 